\title{
Break-up of Gondwana and opening of the South Atlantic: Review of existing plate tectonic models
}

\author{
M. E. Ghidella, ${ }^{1}$ L. A. Lawver, ${ }^{2}$ and L. M. Gahagan ${ }^{2}$ \\ ${ }^{1}$ Instituto Antártico Argentino, Cerrito 1248, C1010AAZ Buenos Aires, Argentina. (mghidella@dna.gov.ar) \\ ${ }^{2}$ Institute for Geophysics, University of Texas at Austin, 10100 Burnet Rd. - R2200, Austin, Texas 78758-4445, U.S.A.(lawver@ig.utexas.edu)
}

\begin{abstract}
The opening history of both the Weddell Sea and South Atlantic Ocean is critical to understanding the breakup of Gondwana and the evolution of Antarctica since Early Jurassic times. The dispersal of the Gondwanide fragments is important to understanding the development of past ocean circulation. Unfortunately the tectonics of the Weddell Sea region is difficult to resolve because of the paucity of data coverage and the region's inherent complexity. Although considerable progress has been achieved in the past 20 years with new marine aeromagnetic data and satellite derived gravity anomaly maps, there are still several models in consideration which differ in crustal ages and schemes of opening. In this paper we present a review of four of those models. Focusing on poles of rotation, synthetic isochrons and flowlines, we proceed backward in time beginning at Chron 34 (83.5 Ma), as it is relatively well defined ocean wide, and present crustal age maps that display the estimated trace of the South America-Antarctica-Africa triple junction for each model. We also plot reconstructions at four selected epochs for all models using the same projection and scale to facilitate comparison. The diverse simplifying assumptions that need to be made in every case regarding plate fragmentation to account for the numerous syn-rift basins and periods of stretching are strong indicators that rigid plate tectonics is too simple a model for the present problem.
\end{abstract}

Citation: Ghidella, M. E., L. A. Lawver, and L. M. Gahagan (2007), Break-up of Gondwana and opening of the South Atlantic: review of existing plate tectonic models, in Antarctica: A Keystone in a Changing World - Online Proceedings of the 10th ISAES, edited by A. K. Cooper and C. R. Raymond et al., USGS Open-File Report 2007-1047, Short Research Paper 055, 5 p.; doi:10.3133/of2007-1047.srp055

\section{Introduction}

How exactly Gondwana broke up continues to be controversial, with a range of rigid plate models invoked. The different models include a variety of proposed segmentations for the South American continent to accommodate various subplates. The timing of final Gondwanide breakup is constrained by seafloor magnetic anomalies and the rotation poles derived from them. The opening of the SW Weddell Sea and the southern South Atlantic are very much linked together. The age of the Paraná-Etendeka hotspot [ 132 Ma] is known and is the same as the earliest seafloor spreading magnetic anomalies in the southern South Atlantic, suggesting that it is improbable that there was a triple junction in the Weddell Sea prior to $132 \mathrm{Ma}$. On the other hand, if there is clear evidence for a medium to deep sea north of the Falkland-Malvinas Plateau earlier than $132 \mathrm{Ma}$, then a triple junction could have been established earlier. Presently, there is conflicting evidence and at least four competing tectonic models. In this paper we make a review of those models. Our method for that is the examination of synthetic isochrons and flowlines. We calculate them backward in time, beginning at Chron 34 $(83.5 \mathrm{Ma})$, as it is a prominent, well defined magnetic anomaly. Subsequently we present maps with synthetic isochrons which exhibit the estimated trace of the South America (SAM) - Antarctica (ANT) - Africa (AFR) triple junction and reconstructions for different sets of finite rotation poles. The reader is referred to figure 1 or to http://ggt.conae.gov.ar/iaa/ipyg/Introduccion for a panoramic view of the region's tectonic framework.

\section{The four models}

Rotation poles are found by reconstructing available observed magnetic anomalies (isochrons) and satellite gravity derived fracture zones (flowlines) in a variety of ways (Hellinger, 1981; Shaw and Cande, 1990; Royer and Chang, 1991). Paleogeographic reconstructions allow for the validation of proposed poles of rotation, by observing the juxtaposition of land masses and by comparison of contiguous geological features that become aligned or adjacent such as orogenic belts, magmatic effusions, igneous provinces, sedimentary basins, older shear or suture zones and other features. Plotting synthetic isochrons and flowlines allow for a visual check of the determined poles as isochrons are compared to magnetic picks or lineations, and tectonic flowlines to known fracture zones. However, when more than two plates are involved, a triple junction is required, and any comparison is not straightforward. For the South Atlantic/Weddell Sea region, such a comparison is useful to point out mismatches in the available reconstructions. Analysis of predicted versus observed plate motions based on a number of prevailing rotation models provides new insights into the evolution of the ANT-AFR-SAM plate system.

Combining AFR-ANT and SAM-AFR plate rotations, Livermore and Hunter (1996) [LH] showed that the trends of the flowlines observed on satellite gravity maps can be approximated by assuming that Weddell Sea floor north of $72^{\circ} \mathrm{S}$ was created entirely by SAM-ANT separation. For the time between initial break-up and M10, their synthetic flowlines, partly based on Martin and Hartnady (1986), imply a predominantly E-W spreading. 


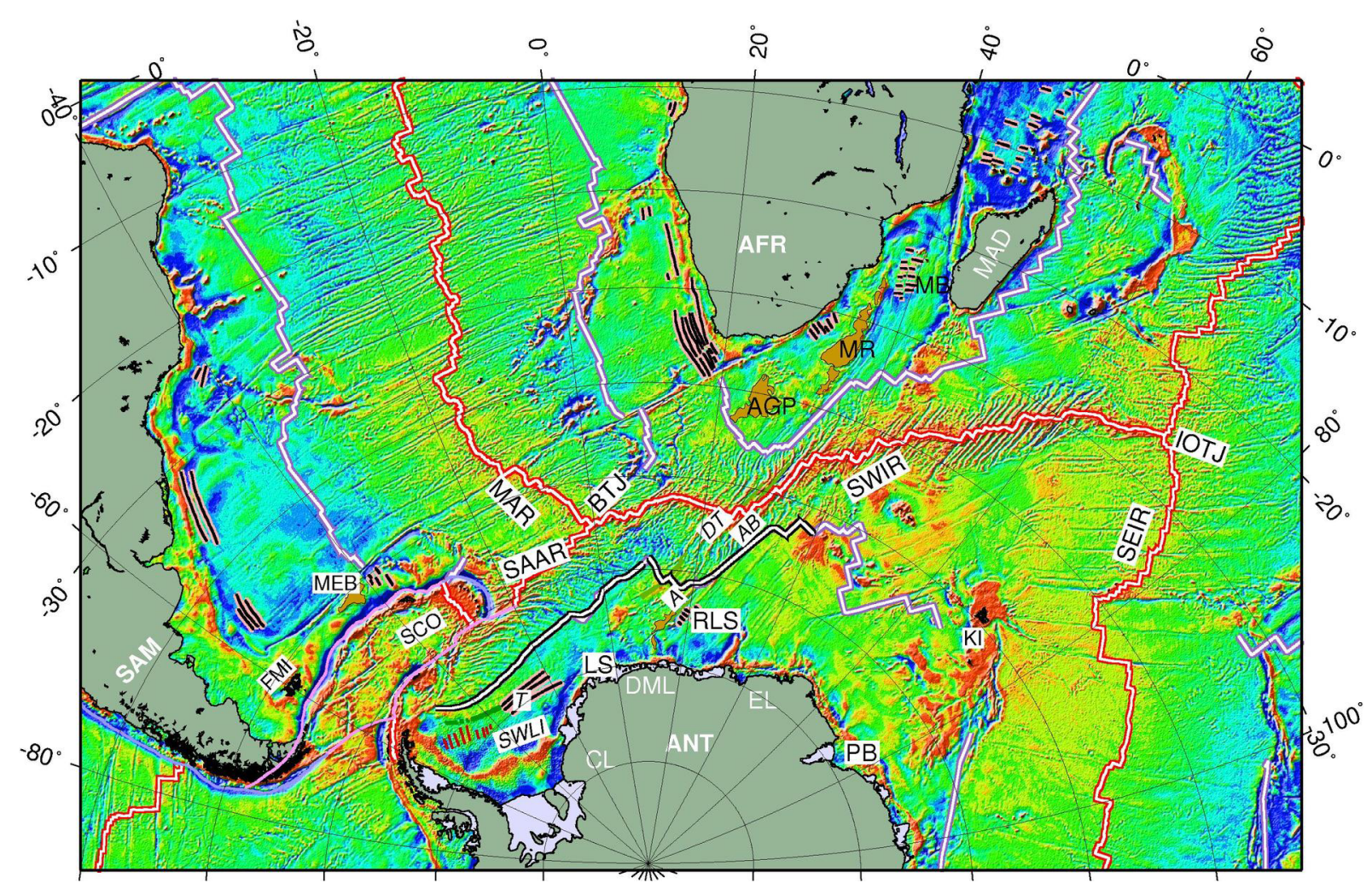

Figure 1. Tectonic Framework - Main features of the Antarctica, South America and Africa spreading systems displayed on a color shaded image of the gravity anomaly field Sandwell and Smith (1997). Some detail is included in the Weddell Sea, as the gravity anomaly T and the magnetic South West striking lineations (SWLI). On the African side we have included the Mozambique Ridge (MR) and the Agulhas plateau (AGP). Some particular fracture zones are labeled: Du Toit (DT), Andrew Bain (AB) and Astrid (A). The thick light lines correspond to the 83.5 Ma isochron from AGEGRID (Müller et al., 1997), on top of which in we have plotted a double black line that joins the selection of $\mathrm{C} 34$ points that we used as seeds for synthetic flowlines. The present day spreading centers are represented by a double red line. The Mesozoic magnetic lineations from Cande et al. (1989) are in thin black on top of red lines. ANT: Antarctica; AFR: Africa; BTJ: Bouvet Triple Junction; CL: Coats Land; DML: Dronning Maud Land; EL: Enderby Land; FMI: Falkland/Malvinas Islands; IOTJ: Indian Ocean Triple Junction; KI: Kerguelen Island; LS: Lazarew Sea. MAD: Madagascar; MAR: Mid Atlantic Ridge; MEB: Maurice Ewing Bank; MB: Mozambique Basin; PB: Pridtz Bay; RLS: Riisen-Larsen Sea; SAAR: South American - Antarctic Ridge; SAM: South America. SCO: Scotia Sea; SEIR: Southeast Indian Ridge; SWIR: Southwest Indian Ridge.

Ghidella and Lawver (1999) presented a model based on the rotation poles developed by the PLATES program (http://www.ig.utexas.edu/research/projects/plates/plates. html) starting with the reconstruction of Gondwana from Lawver et al. (1999) [LGD]. A study of the flowlines generated by the movement of the major plates (SAM AFR - ANT) starting with the tight-fit Gondwana reconstruction produced a two phase opening for the Weddell Sea similar to the one first suggested by Lawver et al. (1985). The first phase produced opening of the southwestern Weddell Sea in a W-E direction with respect to the present position of the Antarctic Peninusla (AP), compatible with the passive non-volcanic morphology of the eastern margin of the AP. For the second phase, an average N-S directed movement results between $132 \mathrm{Ma}$ and $\mathrm{C} 34$.

Ghidella et al. (2002) [GYL] focused on the Western Weddell Sea and derived stage poles under the assump- tion that the Weddell Sea SW striking lineations are imprints of susceptibility contrasts, and then modeled them as fracture zone traces. Numerical experimentation to adjust synthetic isochrons to seafloor spreading lineations and flowlines to fracture zones yielded stage poles for the opening of the Weddell Sea since 160 Ma to anomaly 34 time.

The corresponding reconstructions looked reasonable within the known constraints for the ANT-SAM plate motion. However, closure was not attained between 160 and $118 \mathrm{Ma}$ if independently derived (namely Lawver et al., 1999) EANT-AFR-SAM rotations were considered. The lack of closure could be overcome by considering motion between the Antarctic Peninsula and East Antarctica until $118 \mathrm{Ma}$ time, but then the resulting relative motion contained an important component of convergence.

Jokat et al. (2003) reported on aeromagnetic data col- 
lected along the East Antarctic coast during five seasons. These data close important gaps of magnetic data coverage in critical areas: the Lazarev Sea and the Dronning Maud margin, as well as part of the Riiser-Larsen Sea.

König and Jokat (2006) [KJ] presented a new model that refines the previous one. The model proposes that
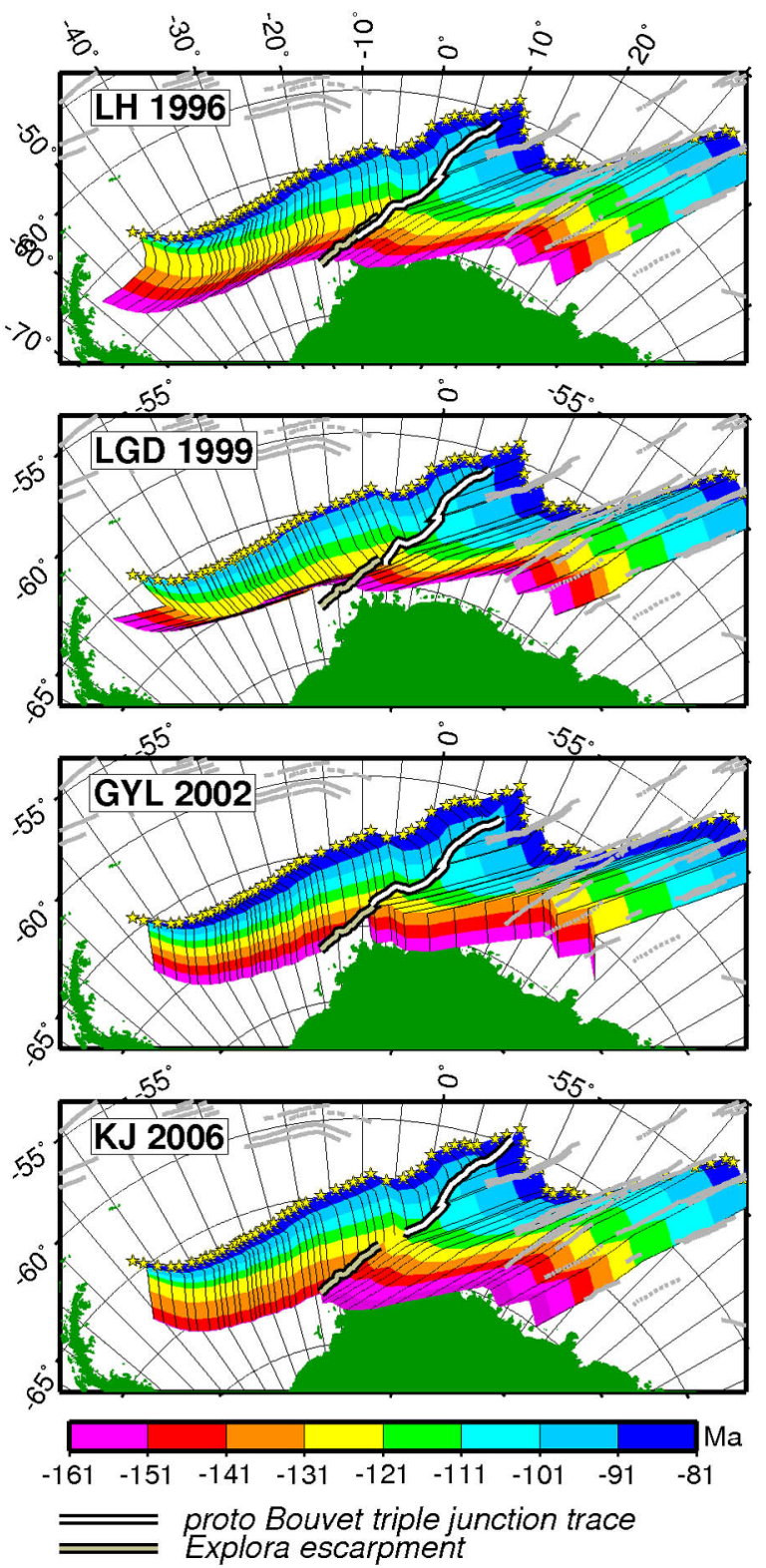

Figure 2. Colored map of crustal ages derived from flowlines and synthetic isochrons, calculated with published rotation poles for each model (see references in text and on figure 3), between C34 time and $160 \mathrm{Ma}$. Yellow stars are the seeds used for the flowlines (a selection of $\mathrm{C} 34$ points). The proto Bouvet trace was determined by the cross-over points between assumed ANT-SAM and ANT-AFR isochrons.

break-up started by rifting in the Somali and Mozambique basins at $\sim 167 \mathrm{Ma}$, accommodated by stretching and extension in a basin comprising continental crust of the
Filchner-Ronne Shelf, the Falkland/Malvinas Island block and the Maurice Ewing Bank. The first true ocean floor in the Weddell Sea is formed at about $147 \mathrm{Ma}$, after the occurrence of rifting between the Antarctic Peninsula and southernmost South America.

\section{Crustal ages for a three plate system}

Under the assumption of a three plate system we calculated synthetic flowlines for the time before Chron 34 . As seeds for the flowlines we used a selection of points created by using a combination of anomaly 34 picks and the 83.5 Ma isochron from AGEGRID version 1.6 (Müller et al., 1997). The selection of points ends at $40^{\circ}$ $\mathrm{E}$, as the points to the east are near the Indian Ocean triple junction trace and correspond to the South East Indian ridge spreading system. The points in the $\mathrm{C} 34$ isochron were separated into two sets: those to the west of the vertex at $10^{\circ} \mathrm{E}$ were considered as seeds for SAM-ANT spreading flowlines; those to the east were taken as seeds for AFR-ANT flowlines. Then we calculated the flowlines using the rotation poles for the four models in steps of 0.1 degrees, from 83.5 Ma to $160 \mathrm{Ma}$. Next we sampled them at a constant time interval of $1 \mathrm{Ma}$, and from these we obtained the synthetic isochrons (Fig. 2).

The SAM-ANT calculated flowlines "invade" AFRANT crust area and vice versa, as there were three plates implicated after the separation between SAM and AFR started, and a triple junction was involved. We estimated the trace of the triple junction by calculating the cross over points between western and eastern isochrons, and clipped both sets of flowlines at the line determined by these points, which we call the pseudo Bouvet (PB) line. This estimation implies a tacit assumption that the branches of the three plates spreading system were ridges (RRR triple junction). Although the present configuration of the Bouvet triple junction is ridge-fault-fault (RFF), its ancestor is considered to have been of the RRR type until about 60-64 Ma (Lawver et al., 1985). For the earlier time the first three models involve a two plates system (West and East Gondwana) whereas in the KJ model there is a first opening in East Antarctica and a second opening in the Weddell Sea 20 Ma later; these rifts evolve independently until $122 \mathrm{Ma}$.

\section{Discussion}

Figure 3 shows the reconstructions calculated for the four tectonic models. Both the LH and LGD models were mainly derived from ANT-AFR magnetic anomalies and satellite gravity-derived fracture zones in the Weddell Sea. Both models started from poles derived for ANTAFR motion, with the ANT-SAM sector calculated using SAM-AFR poles with the ANT-AFR poles. LH show a tighter ANT-AFR fit than LGD with overlap of the Mozambique ridge with the Queen Maud Land continentocean transition crust (COT) and a looser SAM-AFR fit. This difference is due to the trans-continental fragmentation of southern SAM that LGD uses and LH does not. 

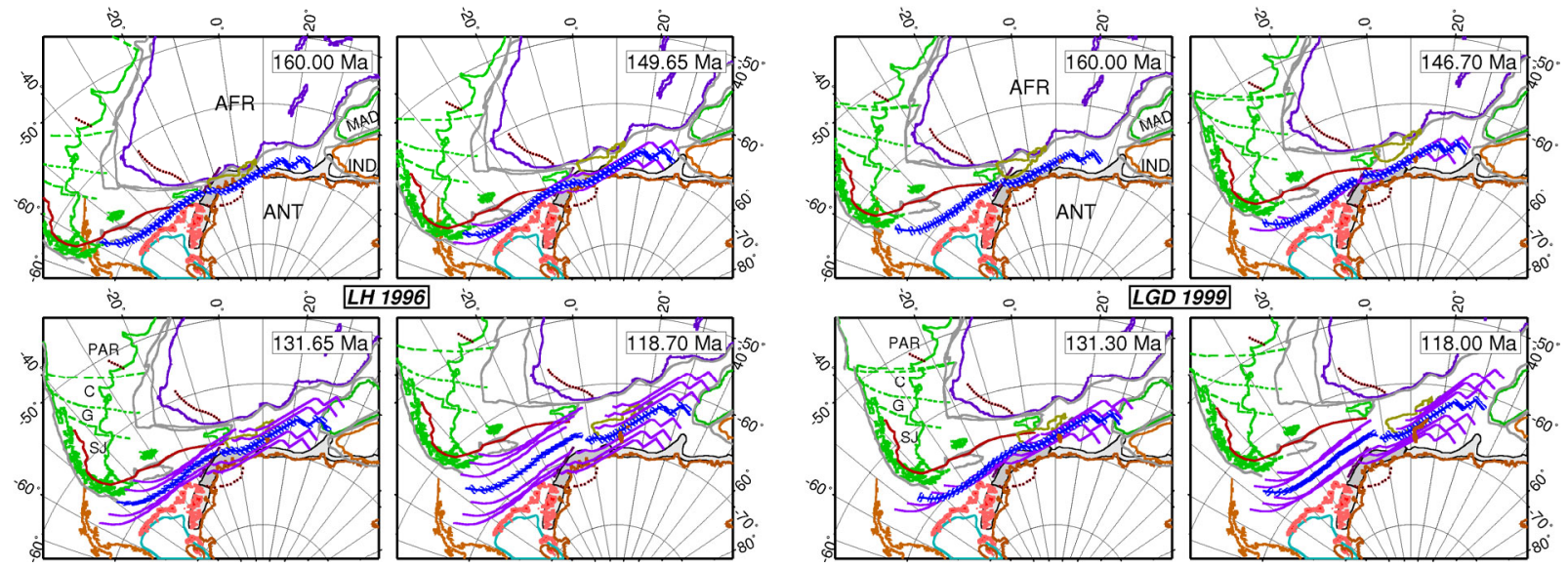

a) Rotations from Livermore and Hunter (1996).
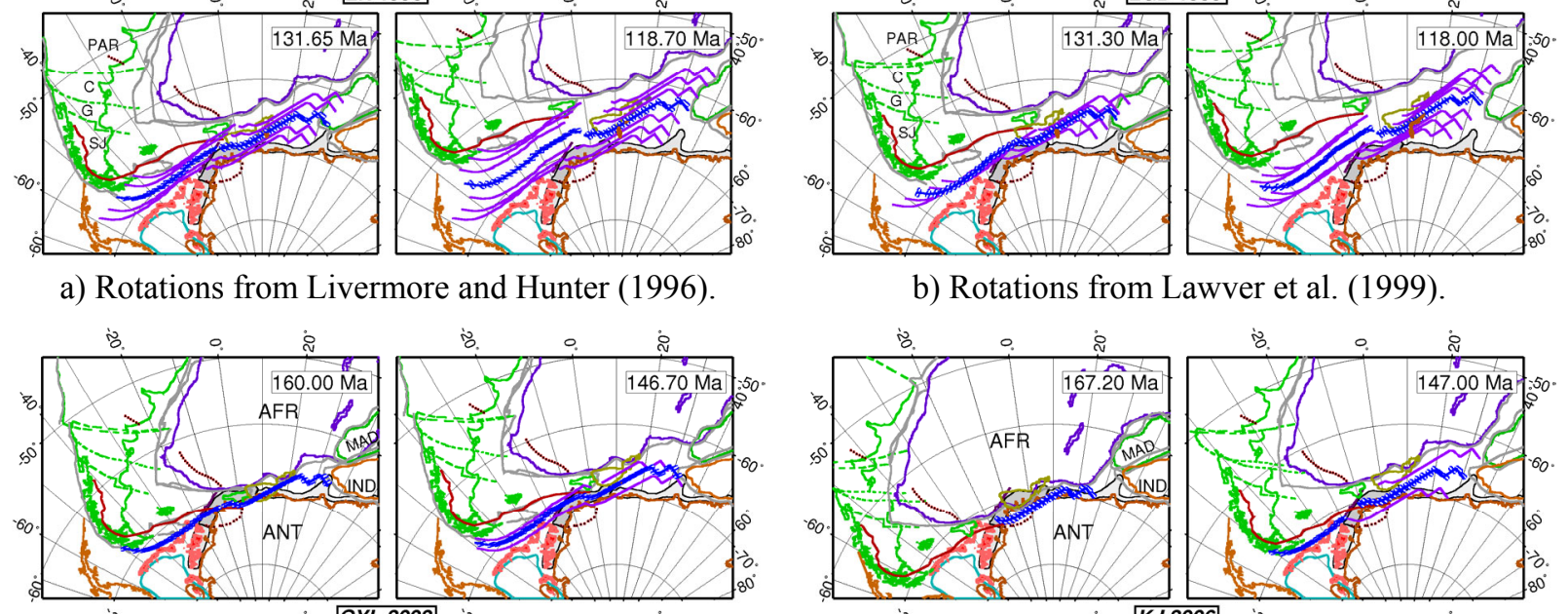

b) Rotations from Lawver et al. (1999).

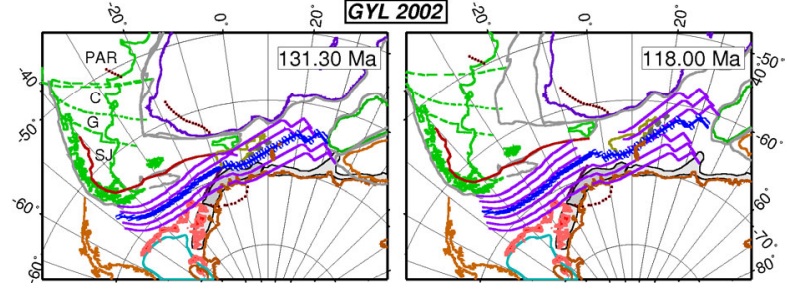

c) Rotations from Ghidella et al. (2002).

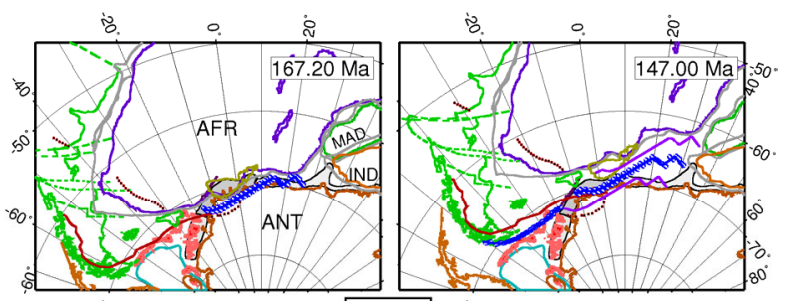

i.

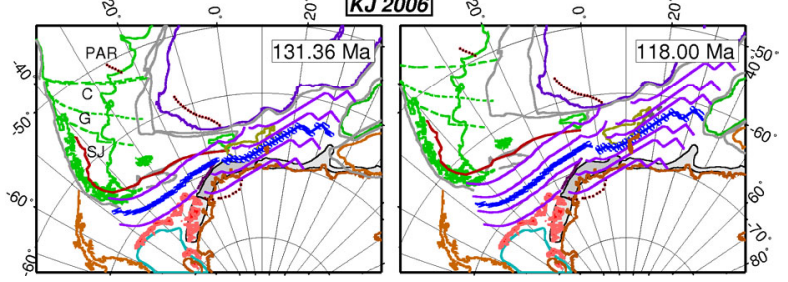

d) Rotations from König and Jokat (2006).

Figure 3. Reconstructions for four rigid plate tectonic models at four selected epochs. Synthetic ANT-SAM and ANT-AFR isochrons are drawn in all cases. For the central isochrons (spreading centers) we have drawn great circle segments for the stage pole at the corresponding time, which represent ridge segments. SAM is fragmented into several subplates following Lawver et al. (1999). PAR, C, G, SJ: Paraná, Colorado, Gastre and San Jorge subplates. Astrid ridge (see figure. 4 for this and other features) is made visible as Antarctica separates from Africa. MAD: Madagascar; IND: India.

The Falkland/Malvinas plateau (FMP) is already stretched in both models.

The southeastern Weddell Sea embayment (WSE) margin has major magnetic anomalies (Orion, Andenes, Explora) which are conjugate with the FMP in LH and nearly so for LGD (looser fit here).

The AP overlaps with southern South America in both models, but that seems unavoidable. Relative motion between the AP block and ANT is needed in both models, more in LH than in LGD. On the ANT-AFR side both models match fracture zones and anomaly picks fairly well. In the west, the LGD flowlines indicate a nearly N-S spreading direction between C34 and $\sim 131 \mathrm{Ma}$, and E-W motion preceding that, due to a major change in the stage pole, resulting from the transition between the two and three plate systems. The LH model exhibits similar be- havior although smoother (allowed by the earlier South Atlantic opening).

The GYL model uses SAM-ANT defined stage poles with the motion mainly N-S in the Weddell Sea. Looking at the flowlines for the ANT-AFR side (Fig. 2) for the GYL model, the result is poor for the time between 160 and $131 \mathrm{Ma}$ with an angle of near $60^{\circ}$ with the fracture zone trends. The Weddell Sea closure $(160 \mathrm{Ma})$ results in the WSE margin anomalies being conjugate with the FMP as in LH. But the juxtaposition occurs more to the west with the already stretched FMP resulting in overlap of the Maurice Ewing Bank (MEB) with the Queen Maud Land COT. The KJ model uses ANT-AFR and ANT-SAM derived poles. It is more recent and has more data to support it than the others. The southern SAM fragmentation may have been active until M10 time. Fragmentation may have been the only way to accommodate the pieces for 


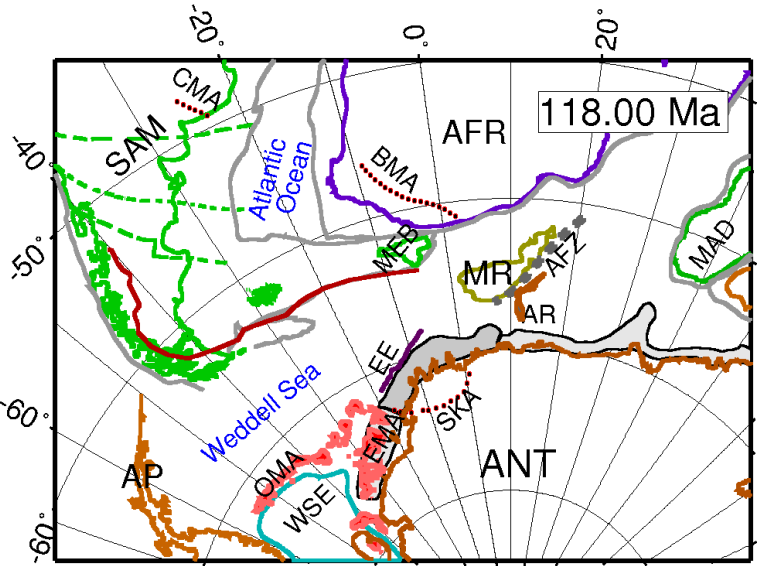

Figure 4. 118 Ma reconstruction, enlarged to display some features not shown in figure. 1. Gray lines delineate the estimated present continent-ocean boundary in SAM and AFR. Gray polygons cover the East ANT continental shelf until the estimated end of the continent-ocean transition. A dark red line in SAM marks the limit of the area to the west and south of which the morphology has most surely changed after breakup. MA: Magnetic Anomaly; FZ: Fracture Zone; ANT: Antarctica; AFR: Africa; AP: Antarctic Peninsula; AR: Astrid Ridge; BMA: Beattie MA; CMA: Claromecó MA; EE: Explora Escarpment; EMA: Explora MA; MEB: Maurice Ewing Bank; MFZ: Mozambique FZ; MR: Mozambique Ridge; OMA: Orion MA; WSE: Weddell Sea Embayment; SAM: South America; SKA: Sverdrupfjella-Kirvanveggen MA.

both independent ANT-SAM and ANT-AFR openings. Two separate and distinct opening phases seem the only way to match the new data (Jokat el al., 2003; König and Jokat, 2006) from the Weddell Sea and the Lazarev Sea to the east of $10^{\circ} \mathrm{E}$. If the initial Gondwana break-up occurred at $\sim 167 \mathrm{Ma}$ in the Somali and Mozambique basins, initial oceanic crust formation in the Weddell Sea may not have begun until $\sim 147 \mathrm{Ma}$, or well after the first break-up of Gondwana. During the $\sim 20$ Ma between the two rifts, motion is accommodated by the strike-slip movement between the SAM subplates as well as by stretching in the FMP and the WSE. The development of a deep water connection between the Indian and the South Atlantic Ocean occurred not before $122 \mathrm{Ma}$. Before this time the Mozambique Ridge, Astrid Ridge and the MEB formed a continental barrier between the oceans in the west and in the east.

\section{Summary}

We have presented a review of four tectonic models for the break-up of Gonwana by exhibiting graphic material as reconstructions and crustal age maps. We do not judge the models; hence we do not declare nor show preference for any of them. We clarify the principal assumptions made in each case, and point out the main differences. Our summary conclusion, is, however, that the diverse simplifying assumptions that need to be made in all cases (i.e. plate fragmentation which is needed to account for the numerous syn-rift basins and periods of stretching), are strong indicators that rigid plate tectonics is too simple a model for the present problem.

\begin{abstract}
Acknowledgements. This work is part of the initial phase of Critical revision of Gondwana break-up for International Polar Year (http://ggt.conae.gov.ar/iaa/ipyg/), an initiative that was submitted to the International Council of Science Planning Group for IPY and is now a subproject of the bipolar Plate Tectonics and Polar Gateways in Earth History (http://platesgates.geo.su.se/) project. We thank Bryan Storey, the co-editor, and two anonymous reviewers who provided insightful comments and suggestions. All figures and part of the processing were made using the Generic Mapping Tools software, (GMT, http://gmt.soest.hawaii.edu/).
\end{abstract}

\section{References}

Cande, S. C., J. L. LaBrecque, R. L. Larson,W. C. Pittman, X. Golovchenko, and W. F. Haxby (1989), Magnetic Lineations of theWorld's Ocean Basins, Am. Assoc. of Pet. Geol., Tulsa, Okla., USA.

Ghidella, M. E., L. A. Lawver, and L. M. Gahagan (1999), Insights into the Central Weddell Sea Herringbone Pattern from Gravity and Magnetics data. Poster presented at the VIII International Symposium on Antarctic Earth Sciences (Wellington, New Zealand), Abstracts Volume, p. 118.

Ghidella, M. E., G. Yáñez, and J. L. LaBrecque (2002), Revised tectonic implications for the magnetic anomalies of the western Weddell Sea, Tectonophysics, 347, 65-86.

Hellinger, S. J. (1981), The uncertainties in finite rotations in plate tectonics, J. Geophys. Res., 86: 9312- 9318.

Jokat, W., T. Boebel, M. König, and U. Meyer (2003), Timing and geometry of early Gondwana breakup, J. Geophys. Res., 108(B9), 2428, doi:10.1029/2002JB001802.

König, M., and W. Jokat (2006), The Mesozoic breakup of the Weddell Sea, J. Geophys. Res., 111, B12102, doi:10.1029/2005JB004035.

Lawver, L. A., J. G. Sclater and L. Meinke (1985), Mesozoic and Cenozoic reconstructions of the South Atlantic. Tectonophysics, 114, 233254.

Lawver, L. A., L. M. Gahagan and I. W. D. Dalziel (1999), Antarctica, Keystone of Gondwana, http://www.ig.utexas.edu/research/projects/plates/movies/akog.ppt

Livermore, R. A., and J. Hunter (1996), Mesozoic seafloor spreading in the southern Weddell Sea, in Weddell Sea Tectonics and Gondwana Break up, edited by B. C. Storey, E. C. King, and R. A. Livermore, Geol. Soc. Spec. Publ., 108, 227-241.

Martin, A. K., and C. J. H. Hartnady (1986), Plate tectonic development of the South West Indian Ocean: A revised reconstruction of East Antarctica and Africa, J. Geophys. Res., 91, 4767-4786.

Müller, R. D.; W.R. Roest, J-Y Royer, L. M. Gahagan, and J.G. Sclater (1997): Digital isochrons of the world's ocean floor. J. Geoph. Res. 102, (B2), 3211-3214.

Royer, J.-Y. and Chang, T. (1991). Evidence for relative motions between the Indian and Australian plates during the last $20 \mathrm{Myr}$ from plate tectonic reconstructions. Implications for the deformation of the Indo-Australian plate. J. Geophys. Res. 96 11779-11802.

Shaw, P. R. and S .C. Cande (1990), High resolution inversion for south Atlantic plate kinematics using joint altimeter and magnetic anomaly data, J. Geophys. Res. 95, 2625-2644.

Sandwell, D.T., and Smith, W.H.F., 1997, Marine Gravity Anomaly from Geosat and ERS-1 Satellite Altimetry, J. of Geoph. Res. 102(B5): 10039-10054. (version 7.2). 